\title{
EFFECTS OF POST-COITAL ADMINISTRATION OF CHLORMADINONE ACETATE TO RATS
}

\author{
A. CASTRO-VAZQUEZ,* ELENA GOMEZ AND J. M. ROSNER $\dagger$ \\ Instituto Latinoamericano de Fisiología de la Reprodución (ILAFIR), Universidad \\ del Salvador, Casilla de Correo 10, San Miguel, Province of Buenos Aires, Argentina
}

(Received 31st December 1973)

\begin{abstract}
Summary. Different doses (ranging from 31 to $1000 \mu \mathrm{g}$ ) of chlormadinone acetate were injected into female rats on Days 2 to 6 of pregnancy. The percentage of ova lost before implantation increased with higher doses of the drug, whereas the implantation ratio (number of rats with implantations/total number of rats) was not affected by treatment. The dose of $1 \mathrm{mg}$ altered the onset of parturition in $50 \%$ of the rats.
\end{abstract}

Since the suggestion by Shelesnyak (1960) that oestrogen secretion is needed for embryo implantation, a pharmacological blockade of this 'oestrogen surge' has been attempted in several ways.

Inhibition of implantation with medroxyprogesterone acetate (Barnes \& Meyer, 1964), tranquillizers (Psychoyos, 1963) or atropine (Schlough, 1969) has been reported. The effect of these drugs was probably mediated through blocking the release of gonadotrophin and the impairment of oestrogen secretion. The administration of oestrogen antagonists also probably produced an antifertility effect by blocking oestrogen action at the level of the uterus (Prasad \& Kalra, 1967). The antifertility activities of various compounds have been correlated with their oestrogenic or antioestrogenic properties (Emmens \& Finn, 1962; Emmens, 1965).

Since chlormadinone acetate (CA) was shown to inhibit oestradiol uptake by the uterus (Rosner, Macome, Denari \& De Carli, 1972), we decided to study the effect of this drug on embryo implantation.

Pro-oestrous rats of the Wistar strain were caged with males overnight, and the following day was regarded as Day 1 of pregnancy if spermatozoa were found in the vagina. Different doses of CA dissolved in $0.5 \mathrm{ml}$ arachis oil were injected subcutaneously daily from Day 2 to Day 6. Rats were killed on Day 7 (the day after implantation), the ovaries and uteri were dissected out and the number of recent corpora lutea and implantation sites were counted. The percentage of ova lost before implantation was calculated for each uterine horn, using the number of recent corpora lutea of the ipsilateral ovary as an index of the number of eggs ovulated. This \% loss was plotted against the corresponding doses of $\mathrm{CA}$ and the equation of the curve was determined by the method of

\footnotetext{
* Fellow of the Consejo Nacional de Investigaciones Científicas y Técnicas, Argentina.

$\dagger$ Member of the Carrera del Investigador, Consejo Nacional de Investigaciones Científicas y Técnicas, Argentina.
} 
Table 1. Implantation ratio in rats treated with chlormadinone acetate

\begin{tabular}{c|c|c}
\hline Dose $(\mu \mathrm{g})$ & No. of rats/group & Implantation ratio* \\
\hline 0 & 10 & 0.80 \\
31 & 5 & 1 \\
62 & 10 & 0.80 \\
125 & 9 & 1 \\
250 & 8 & 1 \\
500 & 10 & 1 \\
1000 & 10 & 0.90 \\
\hline
\end{tabular}

* See text; there were no significant differences (Poisson's test).

least squares (Snedecor \& Cochran, 1969). The implantation ratio (IR = number of rats with implantations/total number of rats) was calculated for each treatment group. Differences between treated and control groups were evaluated by the Poisson's test (Snedecor \& Cochran, 1969). While the IR and the number of implantation sites were not changed by any dose of CA, the $\%$ loss of embryos showed a significant tendency to increase with higher doses of the drug.

A second experiment was performed in order to study the postimplantation fate of embryos in CA-treated rats. A dose of $1 \mathrm{mg}$ was injected daily between

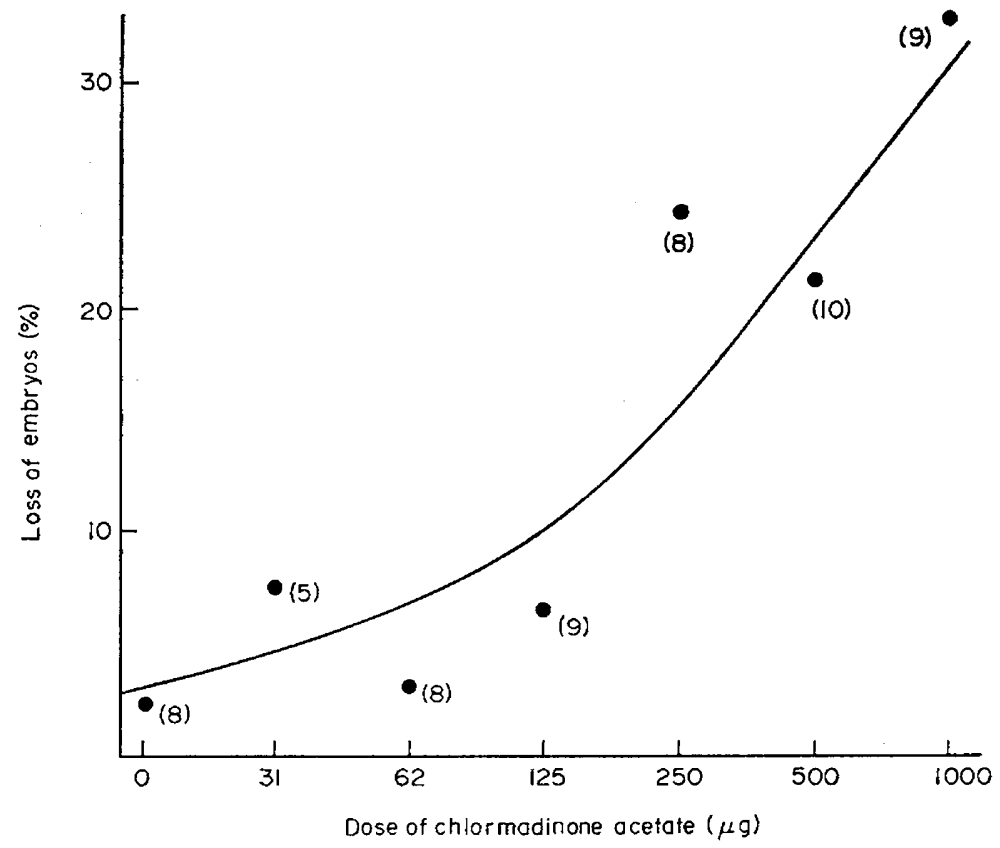

TEXT-FIG. 1. The \% loss of embryos was plotted against the corresponding doses $o$ chlormadinone acetate. The equation of the curve is $y=2.9+0.605 x-0.31 .10^{-4} x^{2}$ with a standard deviation of 5.37. The numbers in parentheses indicate the number of animals per group. Pseudopregnant rats (i.e. rats without implantation sites) were not included. 
Day 2 and Day 6 and pregnancy was allowed to continue until delivery. The ratio between the number of rats giving birth to young and the total number of rats was then calculated (production ratio, $P R$ ). Thirteen out of sixteen control rats produced their young on Day 23, and another one completed parturition on the morning of Day 24. Hence, the PR of the control group was 0.87 . The number of young produced was $9 \cdot 2 \pm 0.6$ (mean \pm S.E.M.). In the CA-treated group, eight out of eleven rats produced offspring $(P R=0.64)$, the mean litter size being $7 \cdot 7 \pm 1 \cdot 1$. Three of them gave birth on Day 24 and the other on Day 22. The percentage of rats having giving birth on abnormal dates was significantly different between the control and the CA-treated group (control: $93 \%$, CA-treated: $50 \% ; P=0.00001$ ).

This investigation was supported by a grant from the Ford Foundation. Chloromadinone acetate was generously supplied by Eli Lilly and Co. of Argentina. The authors wish to thank Dr Eduardo Gavanagh for help in statistical analysis of results.

\section{REFERENCES}

BARNes, L. E. \& MEYER, R. K. (1964) Delayed implantation in intact rats treated with medroxyprogesterone acetate. F. Reprod. Fert. 7, 139.

Emmens, G. W. (1965) Oestrogenic, anti-oestrogenic and anti-fertility activities of various compounds. J. Reprod. Fert. 9, 277.

Emmens, G. W. \& FinN, C. A. (1962) Local and parenteral action of oestrogens and anti-oestrogens on early pregnancy in the rat and mouse. F. Reprod. Fert. 3, 239.

Prasad, M. R. N. \& KAlRA, S. P. (1967) Mechanism of anti-implantation action of anti-oestrogen. Proc. 7 th Conf. Int. plann. Parent. Fedn, Santiago, Chile.

Psychoyos, A. (1963) A study of the hormonal requirements for ovum implantation in the rat, by means of delayed nidation-inducing substances (chlorpromazine, trifluoperazine). F. Endocr. 27, 337.

Rosner, J. M., Macome, J. C., Denari, J. H. \& De Carli, D. N. (1972) Antioestrogenic action of chlormadinone acetate. Acta endocr., Copenh. 69, 403.

Schlovgr, J. S. (1969) Delayed implantation in the rat induced by atropine. Biol. Reprod. 1, 315.

Shelesnyak, M. G. (1960) Nidation of the fertilized ovum. Endeavour, 74, 81 .

SNedecor, G. W. \& Cochran, W. G. (1969) Statistical Methods, 6th edn. Iowa State University Press, Ames, Iowa. 